\title{
Real-world comparative study of behavioral group therapy program vs education program implemented for smoking cessation in community-dwelling elderly smokers
}

\author{
This article was published in the following Dove Press journal: \\ Clinical Interventions in Aging \\ 13 April 2015 \\ Number of times this article has been viewed
}

\section{Chaicharn Pothirat \\ Nittaya Phetsuk \\ Chalerm Liwsrisakun \\ Athavudh Deesomchok \\ Division of Pulmonary, Critical Care and Allergy, Department of Internal Medicine, Faculty of Medicine, Chiang Mai University, Chiang Mai, Thailand}

Correspondence: Chaicharn Pothirat Division of Pulmonary, Critical Care and Allergy, Department of Internal Medicine, Faculty of Medicine, Chiang Mai University, I 10 Inthavaroros Road, Sriphum, Maung Chiang Mai District, Chiang Mai 50200, Thailand

Tel +6653946228

Fax +6653895117

Email cpothira@med.cmu.ac.th; chaicharn.p@cmu.ac.th
Background: Tobacco smoking is known to be an important contributor to a wide variety of chronic diseases, especially in older adults. Information on health policy and practice, as well as evaluation of smoking cessation programs targeting older people, is almost nonexistent.

Purpose: To compare the real-world implementation of behavioral group therapy in relation to education alone for elderly smokers.

Materials and methods: Elderly smokers ready to quit smoking were identified from a cohort who completed a questionnaire at a smoking exhibition. They were allocated into two groups, behavioral therapy ( 3 days 9 hours) and education ( 2 hours), depending on their preferences. Demographic data, the Fagerstrom test for nicotine dependence (FTND) score, and exhaled carbon monoxide level were recorded at baseline. Smoking status of all subjects was followed at months 3, 6, and 12. Statistical differences in continuous abstinence rate (CAR) between the two groups were analyzed using chi-square tests.

Results: Two hundred and twenty-four out of 372 smoking exhibition attendants met the enrollment criteria; 120 and 104 elected to be in behavioral group therapy and education-alone therapy, respectively. Demographic characteristics and smoking history were similar between both groups, including age, age of onset of smoking, years of smoking, smoking pack-years, education level, and nicotine dependence as measured by the FTND scale. The CAR of the behavioral therapy group at the end of the study (month 12) was significantly higher than the education group (40.1\% vs $33.3 \%, P=0.034)$. Similar results were also found throughout all follow-up visits at month $3(57.3 \%$ vs $27.0 \%, P<0.001)$ and month $6(51.7 \%$ vs $25 \%, P<0.001)$.

Conclusion: Behavioral group therapy targeting elderly smokers could achieve higher shortand long-term CARs than education alone in real-world practice.

Keywords: smoking cessation, behavioral, education, elderly

\section{Introduction}

Tobacco smoking is known to be an important contributor to a wide variety of chronic diseases including chronic obstructive pulmonary disease, lung cancer, cardiovascular disease, and cancers of various organs. Tobacco smoking also negatively affects several other respiratory diseases, including pneumonia and pulmonary tuberculosis. ${ }^{1}$ Giving up smoking permanently has been shown to reduce loss of pulmonary function. ${ }^{2-5}$ The reason for high smoking rates, despite the well-known hazards of smoking, is attributable to addiction caused by nicotine dependency as well as habitual addiction. Smoking is now viewed and managed as a drug addiction or chronic disease rather than as a personal habit or hobby. ${ }^{6}$ Thus, effective treatment of tobacco addiction has 
become essential, and a wide range of pharmacologic and non-pharmacologic treatments have been used with varying degrees of success. The most effective approach to smoking cessation appears to result from an appropriate combination of these modalities. ${ }^{7,8}$ Non-pharmacologic interventions to support smoking cessation could be successfully delivered via clinical approaches and through broader public health programs. Certain interventions such as self-help programs, telephone counseling, and cognitive-behavioral therapy are amenable to either individual delivery in the clinical setting or broad dissemination to geographic communities and workplaces. ${ }^{9}$ Smoking cessation rates reported in the literature are usually derived from studies in younger populations, and few studies have been conducted to determine the effectiveness of smoking cessation intervention in older individuals. ${ }^{10-12}$

In Thailand, the prevalence of current smokers in rural areas was significantly higher than urban areas $(29.2 \%$ vs $22.9 \%$ ) with a trend toward increasing prevalence with age. ${ }^{13}$ The prevalence of smoking among Thai adults was $45.6 \%$ for men and $3.1 \%$ for women. $15.8 \%$ of men and $1.7 \%$ of women were current users of roll-your-own (RYO) cigarettes, most of whom were elderly living in rural areas. ${ }^{14}$ Users of RYO cigarettes appeared to be more addicted to smoking than the users of manufactured cigarettes as measured by time to first smoking of a cigarette after waking. ${ }^{14}$ The elderly were reported to be less aware of the harmful effects of smoking, and have higher rates of nicotine dependence. ${ }^{15}$

Behavioral group therapy for smoking cessation is widely reported, but to our knowledge, there is no related information on community-dwelling elderly groups. ${ }^{16}$ Our aim was to evaluate behavioral group therapy and an education-alone program for elderly smokers living in rural communities.

\section{Materials and methods}

A health risk-screening questionnaire was administered to elderly members (age $>60$ years) of the Chiang Dao elderly club, Chiang Dao district, Chiang Mai province. All subjects who aimed to "quit smoking within a month" were invited to a smoking cessation exhibition at Chiang Dao Hospital. The design of the study was observational, including convenience sampling of these elderly smokers. The inclusion criteria were age more than 60 years, current smokers with a smoking history of at least 10 pack-years, and "readiness to quit" state of mind. Exclusion criteria were current pharmacological use to quit smoking, the presence of an unstable or life-threatening medical condition, current unstable psychiatric illness, and alcohol addiction. Participants were allocated into two groups based on their preference: behavioral group therapy (group
A) and education alone (group B) (Figure 1). Both groups attended an education program that included a lecture on the health consequences of smoking for 2 hours. Only group A participants further attended behavioral group therapy sessions for 3 hours per day in the following 3 days, totaling 9 hours. The behavioral therapy program consisted of two parts. The first was a demonstration of formalin-preserved specimens of smoking-related diseases like lung cancer, emphysematous lung, and myocardial infarction with coronary artery occlusion, as well as slides and video clips showing the adverse effects of cigarette smoking in the form of advanced diseases. The second part included coping and social skills training, contingency management, self-control, cognitivebehavioral interventions, reinforcement, and relaxation with a focus on sharing experiences. The participants were equally divided and rotated daily into three stations of video training, behavioral therapy, and socialization, each supervised by two staffs. Subjects who could quit smoking at the end of each day were commended and rewarded with an origami star. Demographic data were collected by face-to-face interview and included age, sex, history of smoking, level of education, economic status, and type of cigarettes smoked. Three levels of economic status were determined based on annual household income: low income $(\leq 70,000$ Baht), moderate (70,001-195,749 Baht), and high income ( $\geq 195,750$ Baht $).{ }^{17}$ The average number of cigarette smoked was, therefore, calculated by dividing the average native cigarette weight by standard manufactured cigarette weight which was equivalent to 4-12 standard manufactured cigarettes. ${ }^{18}$ In addition, native cigarettes consist of crudely cut tobacco mixed with grinded tamarind pod in a loose roll. All participating subjects had their level of nicotine dependency measured by the Fagerstrom test for nicotine dependence (FTND) questionnaire which was validated in many studies, ${ }^{19,20}$ the scale of which consists of six items. ${ }^{21}$ The questionnaires were explicit and informative, and the participants were able to fill them by themselves without supervision. Total possible scores ranged from 0 (no dependence) to 10 (very high dependence) and were categorized as low dependence (score 0-3), medium dependence (score 4-6), or high dependence (score 7-10). 6,22,23

Measuring carbon monoxide (CO) in exhaled breath is an immediate, noninvasive, and well-established method used to classify smokers from nonsmokers. ${ }^{24-26}$ Exhaled CO level was measured using a standardized instrument (the Micro CO Meter, Micro Medical Ltd, Kent, UK) in an open-air environment, ${ }^{27}$ using the standard recommended cut-off value, whereby a reading of 10 parts per million (ppm) or more signifies smoking. ${ }^{24}$ Self-reported smoking 


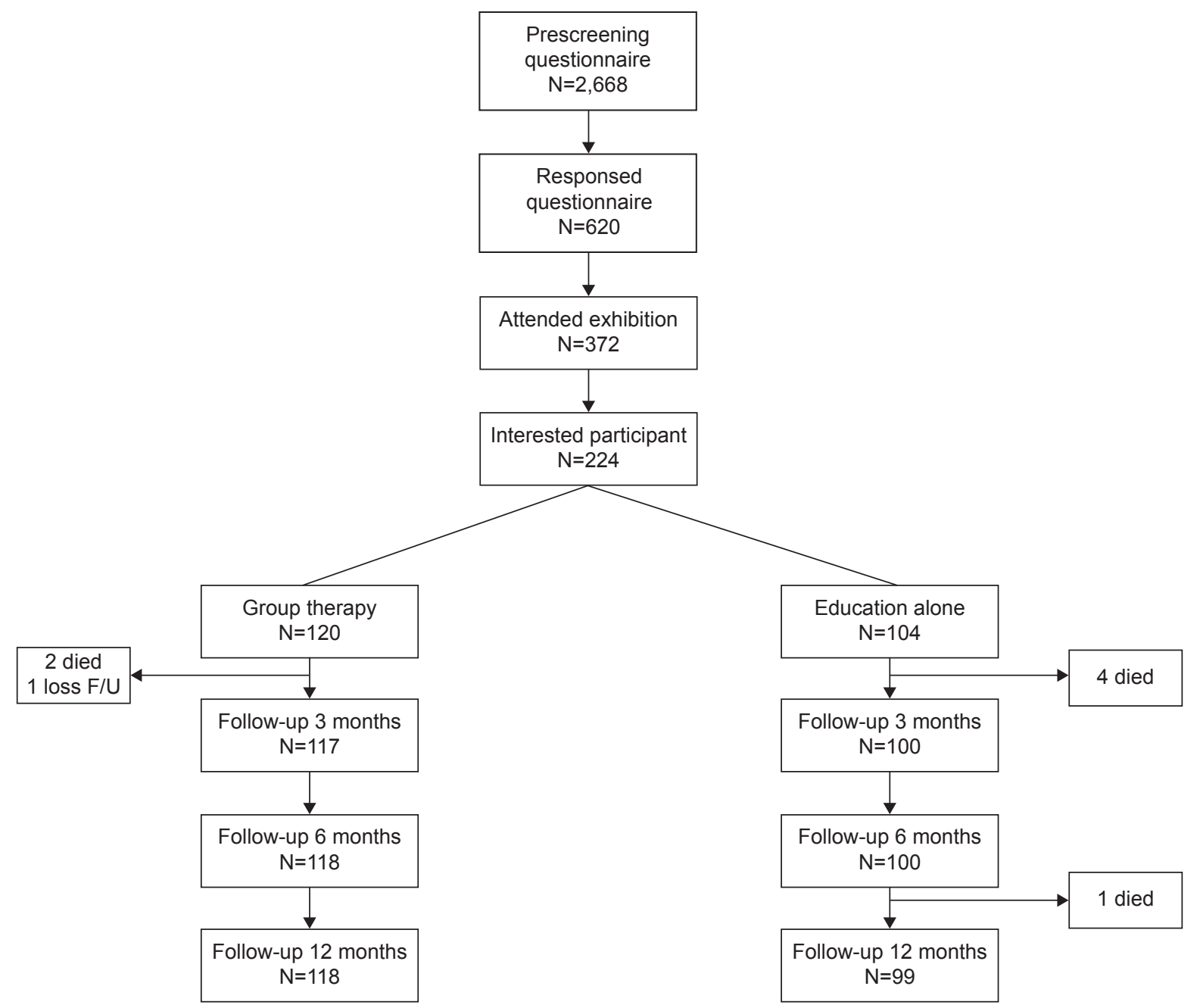

Figure I Flowchart showing subject participation throughout the study. Abbreviation: F/U, follow-up.

status and exhaled CO level were measured at baseline and every follow-up visit at 3, 6, and 12 months post-target quit date (TQD). The primary outcome measured was continuous abstinence rate (CAR) from smoking at the end of month 12 after TQD. Secondary outcomes included CAR at months 3 and 6 after TQD. Continuous abstinence in this study was defined as self-report of not smoking even a single cigarette since TQD and a negative biochemical test (exhaled CO $<10 \mathrm{ppm})^{25}$ at each of the three follow-up visits at months 3,6 , and 12. A participant was defined as a smoker if he/she self-reported smoking $\geq 1$ cigarette or had an exhaled CO level $\geq 10 \mathrm{ppm}$ at each of the three follow-up visits.

\section{Statistical analysis}

Sample size calculation was based on the hypothesis from our pilot study $(n=30)$ in a previous year in which a 12-month cessation rate of $40 \%$ for a behavioral group therapy (group A) and
$15 \%$ for an education-alone group (group B) was found. Based on this report, 88 subjects in each group were required in order to reject the null hypothesis with $95 \%$ power. The type I error probability associated with this null hypothesis was 0.05 , and anticipating a drop-out rate of $15 \%$, it was projected to randomly assign 102 per group. Results for numerical and categorical data were expressed as mean \pm standard deviation and absolute frequencies with percentages, respectively. Independent $t$-tests were used to compare baseline mean differences between the groups. Statistical difference in primary outcome was analyzed using chi-square tests. All analyses were carried out using the SPSS statistical package, version 16 for Windows.

\section{Results}

Six hundred and twenty out of 2,668 elderly subjects initially screened by the health risk questionnaire were responders, and 372 attended our smoking cessation exhibition. Two 
hundred and twenty-four out of 372 attendants demonstrated their readiness to quit within a month by face-to-face interview and were allocated into group A and group B based on their preferences. All study participants smoked RYO native unregulated cigarettes (called Kee-Yo cigarettes) with varying diameters and lengths and had never attempted to quit smoking prior to this study. The schematic diagram of participant enrollment into the study is shown in Figure 1.

Demographic characteristics and smoking history were similar between groups, and there was no significant difference between the groups in terms of age, age of onset of smoking, years of smoking, smoking pack-years, level of education, economic status, and nicotine dependence as measured by the FTND scale (Table 1).

Self-reported smoking status and exhaled $\mathrm{CO}<10 \mathrm{ppm}$ at months 3, 6, and 12 between group A and group B are shown in Table 2. CAR at the end of the study (month 12) was significantly higher in group A than group B (40.1\% vs $33.3 \%, P=0.034)$. Similar results were also found throughout all follow-up visits at months $3(57.3 \%$ vs $27.0 \%, P<0.001)$ and 6 (51.7\% vs 25\%,P<0.001) (Figure 2).

\section{Discussion}

This study revealed that the behavioral group therapy program in elderly smokers resulted in significantly higher CARs, both in short (3-month) and long (6-month and 12-month) terms, than education alone. To our knowledge, there is limited literature on controlled trials comparing behavioral group therapy with education alone. One found no significant differences between the hypnosis, education, or behavioral therapy groups. ${ }^{28}$ Another comparing behavioral group therapy with 1-hour education revealed that behavioral therapy was more effective than education; however, the rates of continuous abstinence for both groups were much lower than our study (25\% vs $13 \%$ at month 3 and $16 \%$ vs $11 \%$ at 1 year). ${ }^{29}$ The major limitation of this study is that participants were not randomly allocated but were self-selected into treatment groups. Setting up a randomized controlled trial (RCT) would be problematic in the community dwellers as there was no travel support or daily wage compensation for those randomized to the behavioral therapy group, which required 3 days attendance. Although this study was randomized, it was designed to simulate a more naturalistic process as subjects could make their own decision in choosing a program most suitable for them. The advantage of this approach was reflected in our study which had very few drop-outs for both groups during the entire study period. Although RCTs are considered to be the gold standard for determining the absolute efficacy of a therapeutic intervention, they do have limitations. ${ }^{30}$ The RCT design can only be applied when it is both feasible and ethical to perform a comparison with the control treatment, and when the patient/subject consents to that element of experimentation. ${ }^{31}$ Thus, most RCTs might not be reliably extrapolated to the real-world situation of

Table I Baseline characteristics and smoking data of study participants

\begin{tabular}{|c|c|c|c|}
\hline \multirow[t]{3}{*}{ Characteristics } & \multicolumn{2}{|c|}{ Total participants $(\mathrm{N}=224)$} & \multirow[t]{3}{*}{$P$-value } \\
\hline & Group A & Group B & \\
\hline & $\begin{array}{l}\text { Behavioral group } \\
\text { therapy }(\mathrm{N}=\mid \mathbf{2 0})\end{array}$ & $\begin{array}{l}\text { Education alone } \\
(\mathrm{N}=104)\end{array}$ & \\
\hline Male sex & $48(40.0 \%)$ & $5 \mathrm{I}(49.0 \%)$ & 0.478 \\
\hline Age (years) & $67.2 \pm 6.7$ & $66.9 \pm 6.5$ & 0.817 \\
\hline \multicolumn{4}{|l|}{ Education } \\
\hline Elementary level & $120(100.0 \%)$ & $104(100.0 \%)$ & - \\
\hline \multicolumn{4}{|c|}{ Level of economic status (Baht/year) } \\
\hline Low $(\leq 70,000)$ & II5 (95.8\%) & $100(96.2 \%)$ & 0.903 \\
\hline Moderate $(70,00 \mathrm{I}-195,749)$ & $5(4.2 \%)$ & $4(3.8 \%)$ & \\
\hline Onset of smoking (years) & $14.9 \pm 9.3$ & $15.8 \pm 8.8$ & 0.476 \\
\hline Duration of smoking (years) & $52.5 \pm 13.3$ & $51.1 \pm 12.7$ & 0.420 \\
\hline Cigarettes per day & $\mathrm{II} . \mathrm{I} \pm 7.3$ & $12.6 \pm 8.4$ & 0.421 \\
\hline Smoking pack-years & $28.1 \pm 11.8$ & $32.2 \pm 12.6$ & 0.401 \\
\hline Exhaled CO level (ppm) & $20.3 \pm 6.6$ & $20.0 \pm 6.9$ & 0.768 \\
\hline \multicolumn{4}{|c|}{ Nicotine dependence (FTND score) } \\
\hline Low (3) & $43(35.8 \%)$ & $40(38.5 \%)$ & 0.105 \\
\hline Moderate (4-6) & $65(54.2)$ & $6 \mathrm{I}(58.6 \%)$ & \\
\hline High $(7-10)$ & $12(10.0)$ & $3(2.9 \%)$ & \\
\hline
\end{tabular}

Note: Data are $\mathrm{n}(\%)$ or mean \pm standard deviation.

Abbreviations: CO, carbon monoxide; ppm, parts per million; FTND, Fagerstrom test for nicotine dependence. 
Table 2 Self-reported smoking status, exhaled $\mathrm{CO}<10$ ppm, and continuous abstinence rate between group therapy and education alone

\begin{tabular}{|c|c|c|c|c|c|c|c|}
\hline \multirow{2}{*}{$\begin{array}{l}\text { Follow-up } \\
\text { (time in } \\
\text { months) }\end{array}$} & \multicolumn{3}{|l|}{ Group therapy } & \multicolumn{3}{|l|}{ Education alone } & \multirow[t]{2}{*}{$P$-value } \\
\hline & $\begin{array}{l}\text { Self-reported } \\
\text { smoking status }\end{array}$ & $\begin{array}{l}\text { Exhaled CO } \\
<10 \text { ppm }\end{array}$ & CAR & $\begin{array}{l}\text { Self-reported } \\
\text { smoking status }\end{array}$ & $\begin{array}{l}\text { Exhaled CO } \\
<10 \text { ppm }\end{array}$ & CAR & \\
\hline Month 3 & $75(64.1)$ & 71 (60.7) & $67(57.3)$ & $31(31.0)$ & $28(28.0)$ & $27(27.0)$ & $P<0.001$ \\
\hline Month 6 & $66(55.9)$ & $65(55.1)$ & $6 \mathrm{I}(5 \mathrm{I} .7)$ & $29(29.0)$ & $26(26.0)$ & $25(25.0)$ & $P<0.00$ I \\
\hline Month 12 & $53(44.9)$ & $50(42.4)$ & $48(40.1)$ & 37 (37.4) & $36(36.4)$ & $33(33.3)$ & $P=0.034$ \\
\hline
\end{tabular}

Notes: Data are $\mathrm{n}(\%)$. P-value indicates the statistically significant CAR between group therapy and education alone.

Abbreviations: $\mathrm{CO}$, carbon monoxide; ppm, parts per million; $\mathrm{CAR}$, continuous abstinence rate.

patients with multiple problems and variable adherence. ${ }^{31}$ CAR, not point prevalence rate, was used as an indicator for evaluation of the effectiveness of the two interventions for the entire study period because it disposed more closely toward the treatment goal: to stop smoking and to maintain abstinence. In contrast to continuous abstinence, point prevalence could ignore extended periods of posttreatment smoking if smoking events did not occur within the "point" window (eg, the last 7 days), thereby considerably overestimating the total number of abstinent subjects. ${ }^{24}$ The high CAR in both groups could be explained by low-to-moderate nicotine dependency in most subjects even though their smoking pack-years were considerably high. The possible reason for low nicotine dependency despite high smoking pack-years was most likely due to error in estimating number of cigarettes smoked. At the end of the study, finding higher CAR in the education-alone group at month 12 than at months 3 and 6 was unexpected. This phenomenon most probably resulted from increased motivation for quitting due to the strong social influence around their workplaces and neighborhoods. The promising results of behavioral group therapy with its relatively short course (3 days) and minimal

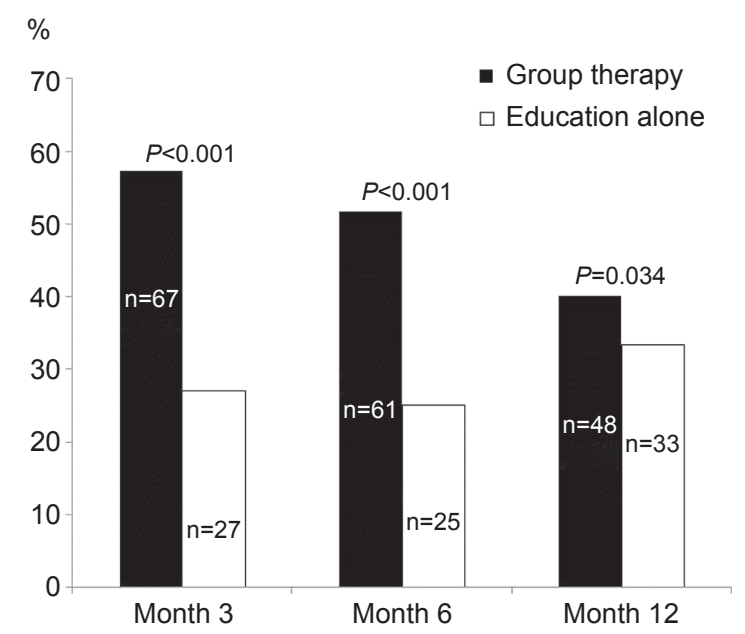

Figure 2 Statistical comparison of continuous abstinence rate between group therapy and education alone. manpower (handling a minimum of 100 participants with only six staff members) as seen in this study highlight that this program can be implemented in resource-limited health agencies like community hospitals.

Our study had several strengths. Firstly, participants were homogeneities for elderly age group without previous attempts to quit, low level of education, low economic status, and smoking the same type of cigarette (RYO cigarette). Secondly, we used biochemical verification by monitoring exhaled CO level for smoking status to confirm self-reported abstinence at every follow-up visit. Thirdly, the study was designed for long-term follow-up with a negligible percentage of patients lost to follow-up compared to a previous study..$^{29}$ Fourthly, the study was designed to simulate realworld practice based on community approach for smoking cessation. However, several limitations in our study need to be mentioned. Firstly, our study could not be designed as an $\mathrm{RCT}$ for the reasons mentioned earlier, and participants in the behavioral therapy group might have more self-control and enthusiasm for coping with their smoking tendencies than the education-alone group. Secondly, all participants in our study were RYO native cigarette smokers. Results might be different from other cigarette brand smokers. Thirdly, the selection of members from the elderly club could affect the external validity of the study and possibly limit our study result for application in different elderly populations. Based on our results, further studies are recommended to evaluate smoking cessation programs in general or other specified elderly populations, and with various cigarette brands. Finally, RCT should be conducted if it is feasible to study the effectiveness of the program for elderly populations.

\section{Conclusion}

Behavioral group therapy focused on elderly smokers in real-world practice resulted in significantly higher short- and long-term CARs than the education-alone group. This promising result could potentially contribute to the widespread 
smoking cessation policy and research for communitydwelling elders.

\section{Acknowledgments}

The authors wish to thank the participants who kindly took part in this study and to acknowledge the staff members of the Division of Pulmonary, Critical Care and Allergy, Department of Internal Medicine, Faculty of Medicine, Chiang Mai University for their contribution to this trial. Their gratitude also goes to Miss Thitaree Liewhiran and Miss Udomsri Kamphor for their contribution in developing the smoking cessation programs and their expertise as skillful counselors for smoking cessation.

\section{Authors' contributions}

The first author developed study design and carried out acquisition and interpretation of data, statistical analysis, manuscript preparation, and critical revision of intellectual contents. The other authors contributed to acquisition and interpretation of data, revision of the article for important intellectual content, and final approval of the version to be published.

\section{Disclosure}

The authors have no conflicts of interest in connection with this work.

\section{References}

1. Tønnesen P, Carrozzi L, Fagerström KO, et al. Smoking cessation in patients with respiratory diseases: a high priority, integral component of therapy. Eur Respir J. 2007;29:390-417.

2. Burchfiel CM, Marcus EB, Curb JD, et al. Effects of smoking and smoking cessation on longitudinal decline in pulmonary function. Am J Respir Crit Care Med. 1995;151:1778-1785.

3. Xu X, Dockery DW, Ware JH, Speizer FE, Ferris BG Jr. Effects of cigarette smoking on rate of loss of pulmonary function in adults: a longitudinal assessment. Am Rev Respir Dis. 1992;146:1345-1348.

4. Camilli AE, Burrows B, Knudson RJ, Lyle SK, Lebowitz MD. Longitudinal changes in forced expiratory volume in one second in adults. Effects of smoking and smoking cessation. Am Rev Respir Dis. 1987;135:794-799.

5. Sherill DL, Holberg CJ, Enright PL, Lebowitz MD, Burrows B. Longitudinal analysis of the effects of smoking onset and cessation on pulmonary function. Am J Respir Crit Care Med. 1994;149:591-597.

6. Heatherton TF, Kozlowski LT, Frecker RC, Fagerstrom KO. The Fagerstrom test for nicotine dependence: a revision of the Fagerstrom Tolerance Questionnaire. Br J Addict. 1991;86:1119-1127.

7. Mallin R. Smoking cessation: integration of behavioral and drug therapies. Am Fam Physician. 2002;65:1107-1114.

8. Stitzer ML. Combined behavioral and pharmacological treatments for smoking cessation. Nicotine Tob Res. 1999;1(suppl 2):S181-S187.

9. Niaura R. Nonpharmacologic therapy for smoking cessation: characteristics and efficacy of current approaches. Am JMed. 2008;121(4 suppl 1): S11-S19.

10. Doolan DM, Froelicher ES. Smoking cessation interventions and older adults. Prog Cardiovasc Nurs. 2008;23:119-127.
11. Tait RJ, Hulse GK, Waterreus A, et al. Effectiveness of a smoking cessation intervention in older adults. Addiction. 2007;102:148-155.

12. Abdullah AS, Lam TH, Chan SK, et al. Effectiveness of a mobile smoking cessation service in reaching elderly smokers and predictors of quitting. BMC Geriatr. 2008;8:25.

13. Palipudi K, Rizwan SA, Sinha DN, et al. Prevalence and sociodemographic determinants of tobacco use in four countries of the World Health Organization: South-East Asia region: findings from the Global Adult Tobacco Survey. Indian J Cancer. 2014;51(suppl 1):S24-S32.

14. Benjakul S, Termsirikulchai L, Hsia J, et al. Current manufactured cigarette smoking and roll-your own cigarette smoking in Thailand: findings from the 2009 Global Adult Tobacco Survey. BMC Public Health. 2013;13:277.

15. Marinho V, Laks J, Coutinho ES, Blay SL. Tobacco use among the elderly: a systematic review and meta-analysis. Cad Saude Publica. 2010;26:2213-2233.

16. Stead LF, Lancaster T. Group behaviour therapy programmes for smoking cessation. Cochrane Database Syst Rev. 2005;2:CD001007.

17. Li L, Borland R, Yong HH, et al. Predictors of smoking cessation among adult smokers in Malaysia and Thailand: findings from the International Tobacco Control Southeast Asia Survey. Nicotine Tob Res. 2010;12(suppl):S34-S44.

18. Pothirat C, Phetsuk N, Deesomchok A, et al. Clinical characteristics, management in real world practice and long-term survival among COPD patients of Northern Thailand COPD club members. J Med Assoc Thai. 2007;90:653-662.

19. Chabrol H, Niezborala M, Chastan E, Montastruc J-L, Mullet E. A study of the psychometric properties of the Fagestrom test for nicotine dependence. Addict Behav. 2003;28(8):1441-1445.

20. Pomerleau CS, Carton SM, Lutzke ML, Flessland KA, Pomerleau OF. Reliability of the Fagerstrom tolerance questionnaire and the Fagerstrom test for nicotine dependence. Addict Behav. 1994;19(1):33-39.

21. Fagerstrom KO, Heatherton TF, Kozlowski LT. Nicotine addiction and its assessment. Ear Nose Throat J. 1990;69:763-765.

22. Fagerström KO, Kunze M, Schoberberger R, et al. Nicotine dependence versus smoking prevalence: comparisons among countries and categories of smokers. Tob Control. 1996;5:52-56.

23. Perez-Rios M, Santiago-Perez MI, Alonso B, Malvar A, Hervada X, de Leon J. Fagerstrom test for nicotine dependence vs heavy smoking index in a general population survey. BMC Public Health. 2009;9:493.

24. West R, Hajek P, Stead L, Stapleton J. Outcome criteria in smoking cessation trials: proposal for a common standard. Addiction. 2005;100:299-303.

25. Jarvis MJ, Tunstall-Pedoe H, Feyerabend C, Vesey C, Saloojee Y. Comparison of tests used to distinguish smokers from nonsmokers. Am J Public Health. 1987;77:1435-1438.

26. Waage H, Silsand T, Urdal P, Langard S. Discrimination of smoking status by thiocyanate and cotinine in serum, and carbon monoxide in expired air. Int J Epidemiol. 1992;21:488-493.

27. Deveci SE, Deveci F, Acik Y, Ozan AT. The measurement of exhaled carbon monoxide in healthy smokers and non-smokers. Respir Med. 2004;98:551-556.

28. Rabkin SW, Boyko E, Shane F, Kaufert J. A randomized trial comparing smoking cessation programs utilizing behaviour modification, health education or hypnosis. Addict Behav. 1984;9(2):157-173.

29. Romand R, Gourgou S, Sancho-Garnier H. A randomized trial assessing the five-day plan for smoking cessation. Addiction. 2005;100: 1546-1554.

30. Evidence-Based Medicine Working Group. Evidence-based medicine: a new approach to teaching the practice of medicine. JAMA. 1992;268: 2420-2425.

31. Pearson M, Barnes N, Thomas M, Tate H, Simnett S. Evaluating the effectiveness of asthma treatment in real-life practice. J Eval Clin Pract. 2004;10(2):297-305. 
Clinical Interventions in Aging

\section{Publish your work in this journal}

Clinical Interventions in Aging is an international, peer-reviewed journal focusing on evidence-based reports on the value or lack thereof of treatments intended to prevent or delay the onset of maladaptive correlates of aging in human beings. This journal is indexed on PubMed Central, MedLine,

CAS, Scopus and the Elsevier Bibliographic databases. The manuscript management system is completely online and includes a very quick and fair peer-review system, which is all easy to use. Visit http://www.dovepress. $\mathrm{com} /$ testimonials.php to read real quotes from published authors.

Submit your manuscript here: http://www.dovepress.com/clinical-interventions-in-aging-journal 